\section{End-of-life programme for older patients in a geriatric step-down hospital}

James KH Luk, MBBS(HK), MSc (Experimental Medicine) (UBC), FRCP (Edin, Glasg, Irel), FHKCP, FHKAM (Medicine), Fei Chan, MBBS(HK), MRCP(UK), FHKCP, FHKAM (Medicine), Felix HW Chan, MBBCh (Wales), MSc(Wales), FRCP(Ire, Glasg, Edin), FHKCP, FHKAM (Medicine)

\begin{abstract}
Objectives. To evaluate the end-of-life (EOL) programme in a geriatric step-down hospital in enhancing dignified death.

Methods. Medical records of patients aged $\geq 65$ years who were admitted to the EOL programme between 24 August 2015 and 31 October 2017 were retrospectively reviewed. The Quality of Dying and Death (QODD) questionnaire was used to assess family member satisfaction of the programme.
\end{abstract}

Results. 235 patients (mean age, 87.9 years) were reviewed. Their principal diagnoses were advanced dementia $(n=118,50.2 \%)$, active cancers $(n=65,27.7 \%)$, organ failure $(n=31,13.2 \%)$, stroke $(n=11$, $4.7 \%)$, and neurodegenerative diseases $(n=6,2.6 \%)$. In the last 24 hours before death, $99.2 \%$ of patients were pain-free, not agitated, and without excessive secretion. Compared with pre-EOL programme, EOL programme significantly reduced the use of intravenous and 'big gun' antibiotics, blood product transfusion, physical restraints, blood tests, haemoglucostix monitoring, and cardiac monitoring (all $\mathrm{p}<0.001$ ). The number of regular medications dropped from 4.8 to 2.6 per patient $(\mathrm{p}<0.001)$. Patients received prompt services from physiotherapists $(88.9 \%)$, occupational therapists $(87.2 \%)$, social workers $(86.4 \%)$, and chaplains (69\%). 90.6\% of carers stayed with patients beyond visiting hours, and $87.7 \%$ were able to say goodbye to their dying relatives. All patients had 'do not attempt cardiopulmonary resuscitation' in place and were not resuscitated. 133 (56.6\%) QODD questionnaires were returned, and the mean score was 8.5 out of 10 .

Conclusion. The EOL programme is useful to foster dignified death and comfort care among dying older patients in a geriatric step-down hospital.

Key words: Hospice care; Terminal care

\section{ORIGINAL ARTICLE}

Department of Medicine and Geriatrics, Tung Wah Group of Hospitals Fung Yiu King Hospital, Hong Kong

Correspondence to: Dr James KH Luk, Consultant, Department of Medicine and Geriatrics, Tung Wah Group of Hospitals Fung Yiu King Hospital, 9 Sandy Bay Road, Pokfulam, Hong Kong. Email:

lukkh@ha.org.hk

\section{INTRODUCTION}

The Hong Kong population is ageing, with those aged $\geq 65$ years amounting to $1,163,153(15.9 \%)$ in $2016 .{ }^{1}$ The number of persons aged $\geq 80$ years increased substantially by $66.7 \%$ over the past decade. Older people often have multiple co-morbidities, and the end-of-life (EOL) issue is inevitable in their disease trajectory. ${ }^{2}$ Patients with organ failure, degenerative neurological diseases, or advanced cognitive 
impairment can have symptoms similar to those with cancers..$^{3-6}$ Enhancing the care for these older patients is related to geriatric medicine., ${ }^{7,8}$ The high mortality of residential care home for the elderly (RCHE) residents has called for the development of EOL services in RCHEs. Since 2015, the Hong Kong West Community Geriatric Assessment Team (CGAT) has started EOL care in RCHEs. ${ }^{9,10}$ However, development of EOL care for older patients in hospital settings has been slow.

Tung Wah Group of Hospitals Fung Yiu King Hospital is a geriatric step-down hospital and provides sub-acute, convalescence, and rehabilitation services. Most patients are from acute medical wards of Queen Mary Hospital. It also accepts older patients from RCHEs who are under the EOL programme of the Hong Kong West CGAT. ${ }^{11-13}$ An internal audit of the hospital showed a mean patient age of 85 years and mortality of $15 \%$. There was a need to enhance EOL care and change to a more palliative approach in providing EOL care for older patients.

The EOL programme included a clinical care plan and a dedicated mixed-sex ward. In 2012, a working group-chaired by a consultant geriatrician and comprising senior and frontline nursing staff, allied health professionals, and chaplains-developed the clinical care plan. ${ }^{14}$ In August 2015, a short-stay mixed ward with eight beds (4 males, 4 females) was built to provide EOL care for older patients. Older patients facing imminent death requiring EOL care are transferred to the EOL ward, as are older patients from RCHEs who are under the EOL programme of the Hong Kong West CGAT.

There is daily ward round by a resident supervised by a senior geriatrician. Unnecessary blood tests, medications, 'big gun' antibiotics, and blood transfusions are curtailed. High-flow oxygen is avoided; oxygen is given for patient comfort rather than for maintaining a high blood oxygen concentration. Cardiac monitoring is minimised. Physical restraint is not used or limited to the shortest possible duration when necessary. Clinical assisted hydration via enteral or parenteral route is maintained unless patients or family members refused. The EOL ward environment emphasises on physical, spiritual, and psychosocial care to foster dignified death. Features of the EOL ward include: warm colour tone walls; two lighting systems with adequate lighting for usual clinical services and soft lighting for patient rest and spiritual care; covered oxygen gas and suction with decoration; individual movable partitions; individual washing basin and television; reclining chair for family members to sit or sleep; small cabinet for storage with mirror in each cabinet; and plastic flowers and plants for decoration. Family members and carers are allowed to stay for 24 hours to accompany the patients. All patients in the EOL ward are seen by physiotherapists, occupational therapists, and social workers. Emotional support and counselling are given by nurses, social workers, and chaplains. Information is given to family members on how to provide EOL care for older patients, expected symptoms during the last stage of life, how to manage the body after death, and where to do death registration. There is a side room for family members to rest and watch television or to perform simple rituals or ceremonies, and for doctors or health care team members to hold family conferences and deliver counselling and bereavement services. After the patient died and the family members emotion settled, satisfaction of the family members was evaluated using the Quality of Dying and Death (QODD) questionnaire. ${ }^{15}$

This study aimed to evaluate the EOL programme in enhancing EOL care for older patients.

\section{METHODS}

This study was approved by the Institutional Review Board of the University of Hong Kong/Hospital Authority Hong Kong West Cluster. Medical records of patients aged $\geq 65$ years who were admitted to and died in the EOL ward from 24 August 2015 to 31 October 2017 were retrospectively reviewed. Information collected included demographic data, principal diagnoses, number of diseases per person, functional and mobility state, mode of feeding, continence state, source of patients to EOL ward, length of stay in EOL ward, symptom control in the last 24 hours, and care after death, as well as whether the patients had advance care planning, 'do not attempt cardiopulmonary resuscitation' (DNACPR) (non-hospitalised), or an advance directive. ${ }^{16}$

We compared pre-EOL programme with post-EOL programme in terms of blood tests, blood product transfusion, blood investigations, haemoglucostix, use of intravenous or subcutaneous 
fluid, physical restraint use, regular medications, and broad spectrum 'big gun' antibiotics usage. For family members or carers, we recorded use of facilities such as the television, the side room, stays in the ward beyond visiting hours, and ability to say goodbye at the last moment of the patient, as well as their QODD score.

Statistical analysis was performed using SPSS (Windows version 23; IBM Corp, Armonk [NY], US). Paired $t$-test and independent $t$-test were used for within-group comparison of continuous variables and the Chi-squared test for comparison of categorical variables. All tests were two-tailed. A p value of $<0.05$ was considered statistically significant.

\section{RESULTS}

A total of 235 patients aged 65 to 107 (mean, $87.9 \pm 8.1$ ) years were included. The mean duration of stay in the EOL ward was 9.0 \pm 9.6 days. The principal diagnoses were advanced dementia $(n=118,50.2 \%)$, active cancers $(n=65,27.7 \%)$, organ failure $(n=31$, $13.2 \%)$, stroke $(n=11,4.7 \%)$, and neurodegenerative diseases $(n=6,2.6 \%)$. The mean number of diseases per person was $4.8 \pm 2.3$. Prior to admission, most patients were living in RCHEs ( $n=171,72.8 \%)$. $55.7 \%$ of patients were widowed. They had poor mobility (23.8\% chair-bound, $59.6 \%$ bed-bound) with marked impairment in functional state $(83 \%$ were totally dependent in their daily activity). $80 \%$ had urinary incontinence and $40.4 \%$ were reliant on enteral feeding.

Of 235 patients, 5 had advance directive before admission. 16 (6.8\%) patients were from the EOL programme of Hong Kong West CGAT and all had DNACPR (non-hospitalized) and advance care planning.

In the last 24 hours before death, $99.2 \%$ of patients were pain-free, not agitated, and without excessive secretion. Compared with pre-EOL programme, the EOL programme significantly reduced the use of intravenous antibiotics ( $85.5 \%$ vs $70 \%, \mathrm{p}<0.001)$, 'big gun' antibiotics ( $54 \%$ vs $41.4 \%, \mathrm{p}<0.001)$, blood product transfusion $(9.4 \%$ vs $1.3 \%$, p $<0,001)$, physical restraints $(21.4 \%$ vs $12 \%, p<0.001)$, blood tests $(72 \%$ vs $13 \%, \mathrm{p}<0.001)$, haemoglucostix monitoring ( $34 \%$ vs $13.7 \%, \mathrm{p}<0.001$ ), and cardiac monitoring ( $6 \%$ vs $0.85 \%, \mathrm{p}<0.001)$. The number of regular medications dropped from 4.8 to 2.6 per patient $(\mathrm{p}<0.001)$. However, there was no significant difference in the use of parenteral hydration and enteral feeding. Only four patients who required parenteral hydration were on hypodermoclysis. Patients received prompt services from physiotherapists (88.9\%), occupational therapists $(87.2 \%)$, social workers $(86.4 \%)$, and chaplains (69\%). $90.6 \%$ of carers could stay with patients beyond visiting hours. $79.6 \%$ of family members or carers used the side room for rest, and $76.6 \%$ watched television. $87.7 \%$ of family members were able to say goodbye to their dying relatives. All patients had DNACPR order in place and were not resuscitated. 133 (56.6\%) QODD questionnaires were returned; the mean score was $8.5 \pm 1.6$ out of 10 .

\section{DISCUSSION}

This study demonstrated the merits of EOL programme in a geriatric step-down hospital in providing EOL care for older patients. In contrast to palliative care programmes typically for younger cancer patients, most of our patients had advanced dementia, organ failure, or stroke, and only $27.7 \%$ of patients had cancers. The EOL programme in the geriatric step-down hospital changed the management approach from curative to palliative.

The EOL programme reduced potentially painful and suffering interventions to dying patients, avoided unnecessary medications and interventions such as intravenous antibiotics, particularly 'big gun' antibiotics, and minimised blood tests, blood product transfusions, regular medications, and unnecessary vital sign monitoring (including haemoglucostix) and physical restraints.

In the EOL programme, patients were given oral hydration and feeding. If the patients could not tolerate oral route, the pros and cons of clinical assisted hydration (enteral or parenteral route hydration) were discussed and given unless objected to by patients or family members. Most family members did not object to clinical assisted hydration at the last few days of the patient's life. Therefore, enteral feeding (mostly via a nasogastric tube) and intravenous drip were not reduced after the EOL programme. Hypodermoclysis (subcutaneous infusion of fluids) is a safe, useful, and easy clinical assisted hydration technique suitable for dehydrated older patients. ${ }^{17}$ Only four of our patients who required parenteral 
hydration were on hypodermoclysis. In future, education and promotion of hypodermoclysis is warranted, so as to enhance the use of clysis. Feeding problems are common, particularly in those with advanced dementia. Tube feeding does not prolong survival of patients; rather it leads to patient discomfort and increased use of physical restraint. ${ }^{18}$ Therefore, careful hand feeding has been used in our hospital to reduce the reliance of tube feeding. ${ }^{19}$

In the EOL ward, $90.6 \%$ of carers stayed with patients beyond visiting hours. Most watched television and used the side room for rest. Spiritual, psychosocial, and bereavement needs of the patients and family members were assessed by nurses. Most patients and family members could be seen by physiotherapists, occupational therapists, social workers, and chaplains before the patient died. Although a pan-referral approach was used for the multidisciplinary team in EOL programme, some patients died quite quickly before being seen by allied health professionals.

For dying patients, being able to say goodbye to family members at the last moment is one element of a 'good death'. ${ }^{20}$ Saying goodbye with a caring touch is an important farewell ritual among Hong Kong Chinese. ${ }^{21}$ Failure to do so might lead to guilty feelings. In the EOL programme, $87.7 \%$ of family members could say goodbye to their dying relatives. After the family members calmed down from their grief, nurses would provide information about procedure after death to them. This helped to reduce feelings of anxiety and helplessness. The high QODD scores confirmed that the EOL programme was welcomed by most family members.

There were several limitations in the present study. We compared the same group of patients. A better study design would be a prospective study with a control arm. We documented the change of medical practices before and after the EOL programme, but did not measure other palliative strategies including the use of oxygen, types of drugs given for comfort care, and the use of morphine. Being a retrospective study, data accuracy is reliant on the quality of documentation in the case notes. Patients included were frail older Chinese people with multiple medical illnesses. Results of this study may be generalisable to other hospitals serving older Chinese patients with similar disease profile.

\section{CONCLUSION}

The EOL programme is useful to foster dignified death and comfort care among dying older patients in a geriatric step-down hospital. It marked reduced unnecessary interventions and investigations. The EOL programme might also be useful in general medical and surgical wards in acute hospitals. Further prospective randomised controlled trials are warranted to determine the benefits of the EOL programme for older patients.

\section{ACKNOWLEDGEMENT}

We would like to thank all nurses in Tung Wah Group of Hospitals Fung Yiu King Hospital for helping to implement the EOL programme, in particular, Ms DYF Lo and Ms A Kwan for data collection.

\section{DECLARATION}

The authors have no conflict of interest to disclose.

\section{REFERENCES}

1. Hong Kong 2016 Population By-census: Thematic Report: Older Persons. Hong Kong: Census and Statistics Department, the Government of the Hong Kong Special Administrative Region.

2. Luk JK, Chan WK, Ng WC, Chiu PK, Ho CK, Chan TC, et al. Mortality and health services utilisation among older people with advanced cognitive impairment in residential care homes. Hong Kong Med J 2013;19:518-24. Crossref

3. Gibbs LM, Addington-Hall J, Gibbs JS. Dying from heart failure: lessons from palliative care. Many patients would benefit from palliative care at the end of their lives. BMJ1998;317:961-2. Crossref

4. Caird FI. The importance of psychological symptoms in Parkinson's disease. Age Ageing 1999;28:335-6. Crossref

5. Mitchell SL, Kiely DK, Hamel MB, Park PS, Morris JN, Fries BE. Estimating prognosis for nursing home residents with advanced dementia. JAMA 2004;291:2734-40. Crossref

6. Marsh GW, Prochoda KP, Pritchett E, Vojir CP. Predicting hospice appropriateness for patients with dementia of the Alzheimer's type. Appl Nurs Res 2000;13:187-96. Crossref

7. World Health Organization Regional Office for Europe. Palliative care for older people: better practices. Copenhagen; 2011.

8. Luk JK, Liu A, Ng WC, Lui B, Beh P, Chan FH. End-of-life care in Hong Kong. Asian J Gerontol Geriatr 2011;6:103-6.

9. Luk JK, Chan FH. End-of-life care for advanced dementia patients in residential care home: a Hong Kong perspective. Ann Palliat Med 2018;7:359-64. Crossref

10. Luk JK. End-of-life services for older people in residential care homes in Hong Kong. Hong Kong Med J 2018;24:63-7. Crossref

11. Luk JK, Liu A, Ng WC, Lui B, Beh P, Chan FH. End-of-life care: towards a more dignified dying process in residential care homes for the elderly. Hong Kong Med J 2010;16:235-6.

12. Ho AH, Luk JK, Chan FH, Chun Ng W, Kwok CK, Yuen JH, et al. Dignified palliative long-term care: an interpretive systemic framework of end-of-life integrated care pathway for terminally ill Chinese older adults. Am J Hosp Palliat Care 2016;33:439- 


\section{Crossref}

13. Luk JK, Pau MM, Chan FH, Yu C. Outreach geriatric private nursing home service in Hong Kong Central and Western cluster. J Hong Kong Geriatr Soc 2002;11:5-10.

14. Luk JK, Chan TC, Mok WW, Wong EK, Chan FH. End-of-life clinical plan in a geriatric step-down hospital. Asian J Gerontol Geriatr 2016;11:42-7.

15. Downey L, Curtis JR, Lafferty WE, Herting JR, Engelberg RA. The Quality of Dying and Death Questionnaire (QODD): empirical domains and theoretical perspectives. J Pain Symptom Manage 2010;39:9-22. Crossref

16. Chu LW, Luk JK, Hui E, Chiu PK, Chan CS, Kwan F, et al. Advance directive and end-of-life care preferences among Chinese nursing home residents in Hong Kong. J Am Med Dir
Assoc 2011;12:143-52. Crossref

17. Luk JK, Chan FH. Is hypodermoclysis suitable for frail Chinese elderly? Asian J Geront Geriatr 2008;3:49-50.

18. Luk JK, Chan DK. Preventing aspiration pneumonia in older people: do we have the "know-how"? Hong Kong Med J 2014;20:421-7. Crossref

19. Luk JK, Chan FH, Hui E, Tse CY.The feeding paradox in advanced dementia: a local perspective. Hong Kong Med J 2017;23:30610. Crossref

20. Smith R. A good death. An important aim for health services and for us all. BMJ 2000;320:129-30. Crossref

21. Chan CL, Chow AY. Death, Dying and Bereavement: a Hong Kong Chinese Experience. Hong Kong: Hong Kong University Press; 2006. 